\title{
Critical barriers impeding the delivery of Physical Education in Zimbabwean primary and secondary schools.
}

\author{
Edmore Nhamo ${ }^{1}$, Tinny Margaret Muswazi ${ }^{2}$ \\ ${ }^{1}$ (Lecturer, Physical Education and Sport Unit, Department of Health Sciences, Faculty of Science and \\ Technology, Zimbabwe Open University, Bulawayo, Zimbabwe) \\ ${ }^{2}$ (National Programme Leader, Physical Education and Sport Unit, Department of Health Sciences, Faculty of \\ Science and Technology, Zimbabwe Open University, Harare, Zimbabwe)
}

\begin{abstract}
This article reviews and analyses the critical factors that have contributed to the trivialisation and the consequent non teaching of Physical Education in Zimbabwean primary and secondary schools. The paper analyses and reviews relevant Zimbabwean studies and literature in order to come up with a pattern that explains the major reasons for the non teaching of this significant, but often neglected subject. The paper also projects forward by presenting practical suggestions for improvement of the status quo.

Keywords: Physical education delivery, impeding factors, primary and secondary schools, Zimbabwe
\end{abstract}

\section{Introduction And Background}

The need for appropriate status and adequate resources for school Physical Education (PE) has been expressed repeatedly by major international organisations, high level policy, decision makers and experts in the research and practice of various fields of education [1]. These include inter alia, UNESCO, the International Olympic Committee (IOC) and the International Council for Sport Science and Physical Education (ICSPE) as well as several regional sports organisations[1]. For example the International Charter of Physical Education and Sport adopted by UNESCO declare that the practice of Physical Education and Sport is a fundamental human right for all [2].

In compliance with the World Health Organisation (WHO) policy of 1998 [1] and the United Nations Charter [2] the Zimbabwean Government crafted policies which make the teaching of Physical Education (PE) compulsory in Zimbabwean schools [3,4,5]. However in spite of the existence of such compulsive policies the situation on the ground shows that PE is still not being taught in Zimbabwean schools and in a few isolated cases where it is being taught it appears the subject is not being taught effectively. It is against this background that this paper reviews the critical factors that are affecting the delivery of PE in both primary and secondary schools in Zimbabwe. This paper is guided by the following research questions:

a. What are the factors that affect the teaching of PE in primary and secondary schools in Zimbabwe?

b. What strategies can be put in place to promote the teaching of PE in Zimbabwean primary and secondary schools?

The structure of the paper is based on the following main headings and subheadings:

1. Introduction and background

2. Methodology

3. Findings

$>$ Historical influences

$>$ PE facilities and equipment

$>$ PE teachers' training curricular

$>$ Attitudes towards PE

$>$ PE knowledge

$>$ Misconceptions about PE

$>$ The PE syllabus and teaching materials

4. Conclusion

5. Recommendations

\section{Methodolgy}

This paper is based on a review and content analysis of relevant literature and policies for purposes of identifying the critical factors that impede the teaching of PE in Zimbabwean primary and secondary schools and also come up with possible solutions. 


\section{Findings}

The review led to the identification of the following main thematic ereas which explain the reasons behind the non teaching of PE in Zimbabwean primary and secondary schools:

\subsection{Historical influences}

The teaching of PE and Sport in Zimbabwe seems to be suffering from both local and global historical influences. The global influences span back to the ancient times of human existence. While Sport was somewhat organised in ancient Zimbabwe, generally there were no organised Physical Education (PE) programmes as such in primitive society nor in the culture of any ancient nations. Apprenticeship was the main mode of PE instruction in these societies [6]. Physical Education was generally encouraged for military training in most oriental ancient nations [6] and in the african ancient nations PE was mainly encouraged for military and hunting purposes. It can be concluded that PE per ser was less essential in the lives of many ancient people, but was undertaken as an indirect instrument of human survival. In Egypt for example, PE was regarded merely as training in certain physical skills, such as swimming for recreational purposes and dancing for religious purposes among people of higher social classes, and as training in motor skills required by their jobs among people of lower social classes [6].

It is also noted that in the dark ages PE activities were affected by two particular movements i.e. asceticism and scholasticism. Scholasticism is the belief that facts are the most essential iterms of one's education [7]. The belief de-emphasized the physical as being unimportant and unnecessary [7]. It is apparent that the concept of scholasticism seems to have been passed down from generation to generation and its influnce is apparent in today's PE activities the world over [7]. Asceticism on the other hand refers to an early christian concept based on the belief that evil existed in the body and therefore the body should be subordinated to the spirit which was pure [7]. In line with asceticism the body was believed to be possessed by evil and hence must be tortured. The implication of asceticism was that any institution associated with this concept would not allow PE to be part of its curriculum [6].

In the history of Zimbabwe the colonial legacy of inequalites based on race, marginalised the blacks who formed and still form the majority of the population in the political, economic and cultural domains [6]. The disciplines of PE, Sport and Culture were heavily characterised by ills of injustice, racial discrimination and prejudice [6] emanating from the colonial legacy. During the colonial period PE was not valued by the majority of blacks since it was viewed as play, controlled by whites, elitist and was based on western activities, values and beliefs [6]. It can be observed that while Zimbabwean PE activities have undergone some tranformation and metamorphosis towards the better the discipline is still being haunted by the historical influences articulated above.

\subsection{PE facilities and equipment}

Research conducted by the Nziramasanga commission of inquiry into eductaion and training in 1999 in Zimbabwe revealed that most PE and Sport facilities in primary schools particulary in rural areas, farming areas and high density surbubs are substandard and inadequate [8]. Evidence was also availed to the commission to suggest that the equipment required for teaching PE are expensive and not easily available [8]. The evidence provided to the commission showed that there is no financial provision for the development of PE and that the general-purpose funds in Zimbabwean schools are too little to support any meaningful PE programmes [8]. The same sentiments are echoed by Musangeya, Kupara, Tanyongana and Mumvuri [6] who say that the successful implementation of the PE syllabus has been adversely affected by inadequate facilities, equipment, instructional materials and finance. While the literature reviewed here may seem outdated it is the authors' contention that the findings are still valid and relevant to the situation currently prevailing in Zimbabwe and the situation could actually be worse off now than it was then. This situation could have been exacerbated by the fact that Zimbabwe is reported to have experienced decades of sustained and severe economic decline from around the year $2000[9,10]$ making it difficult for the government in general and schools in particular to have made any meaningful investment in PE equipment and facilities from that time to date. Currently Zimbabwe is experiencing high rates of unemployment, liquidity challenges, low capacity utilization of around $40 \%$ in the productive sector, massive closure and downsizing of companies and persistent droughts. The Zimbabwean government has been and still is presiding over an economy which is on a tailspin owing to poor performance of key sectors. It is therefore futile for anyone to expect a government which had and still has its hands full with more immediate economic challenges to have made or make any substantial and meaningful investments in PE equipment and facilities.

The Curriculum development Unit (CDU) [11] also conducted a survey on PE lecturers and student teachers and made similar findings as those discussed above. The CDU [11] reports that both the lecturers and student teachers surveyed expressed concern about the lack of basic facilities and equipment in former group B (African schools) and the deteriorating state of facilities in former group A (European schools) because of lack 
of care or refurbishment. The study also revealed that only a few schools have a swimming pool, tennis court and basketball court making it impossible to teach these and many other activities in PE lessons [11].

\subsection{PE teachers' training curriculum}

It has been observed that not much research and evaluation has been carried out on PE programmes in teachers' training colleges in Zimbabwe [8]. The situation during the period of the Nziramasanga [8] research indicated that there was no special entry for enrolling student teachers in PE training [8].This situation is no different today as it was then because there are still no special entry requirements for one to do PE at teachers' colleges in Zimbabwe thereby making the earlier research findings quite contemporary. This is so because there is still no public examination in PE in primary and secondary schools in Zimbabwe hence it is not mandatory for one to have done PE at primary or secondary school to be enrolled for PE training at teachers' colleges [8]. Most students who enroll for PE training do so as a last resort [11] usually after failing to secure places in other college departments generally perceived as more scholastic or academic.

Nziramasanga [8] observed that while all primary school teachers do Physical Education (PE) at college, the majority of these primary school teachers themselves pointed out that they do not have the necessary competencies to teach PE effectively. The training which the student teachers receive at college during their initial training does not make them specialists teachers of the subject [8]. This view is supported by Musangeya et al [6], who also observed that teachers' training colleges that train PE teachers mainly produce non specialist teachers and a few PE specialist teachers for primary schools. The CDU [11] also explains that the lecturers surveyed in their study were of the opinion that the specialist PE teachers produced by the colleges were not as many and as competent as they wished because most colleges are understaffed or staffed with under-qualified or unqualified lecturers. In addition the students who mostly have a poor PE background do not specialize in PE only since they have to do other academic subjects because of the general shortage of teachers in the country [11] and the general nature of the teachers' training curriculum. However it is important to note that this situation could have changed slightly since Zimbabwe now has student teachers doing double majors in PE in secondary school teachers' colleges like Hillside and Belvedere, but the situation in primary school teachers' colleges remain unchanged.

The evidence provided to the commission also showed that physical education programmes in colleges are neither standardized nor comprehensive.

\subsection{Attitudes towards PE}

One of the major problems affecting the teaching of PE is the usually covert though sometimes overt widely reported negative attitudes of senior administrators, education officers, heads of schools, some teachers, parents and other key stakeholders towards the subject [6]. The reasons given for such negative attitudes include lack of knowledge of what PE is as well as its purpose and benefits $[6,10]$. The lecturers and students surveyed also blamed the Zimbabwean colonial past, discussed above, as contributing to the negative attitudes [11].This is because in Zimbabwean African schools PE was given little emphasis and was constructed as a worthless subject in an entirely academic curriculum [11]. The absence of public examination in the subject and lack of defined career paths in PE was also regarded as a reason for the negative attitudes towards the subject [11].

\subsection{PE knowledge}

The increasing under-utilization of the opportunities offered by schools to provide adequate PE and physical activity is caused by several factors [1]. The basic reason given being ignorance of the importance of physical activity for young people. This in turn is considered to be largely due to the fact that policy and decision makers, teachers and other professionals, parents and various other concerned stakeholders and organizations have no adequate knowledge of the need for PE, physical activities and its benefits for the present and future health and well being of young people [1].

\subsection{Misconceptions about PE}

The dearth of knowledge explained above have also contributed to a lot of misconceptions about PE which in turn adds to the low status and subsequent non teaching of the subject. The following are some of the most commonly reported misconceptions about PE:

Some people believe that PE is for dull students [12]. This stems from the misguided view that PE is concerned with the physical and not the intellectual, social and emotional objectives of education. Its teachers are often also labeled as dull [12]. This belief de-emphasizes the physical as being subordinate to academic (scholastic) work. This also arises because PE is not normally done in the classroom, does not have written exercises, homework, tests or internal or public examinations [12]. However as argued by Bucher and Thaxton [13] this belief is not true because PE have been proved to meet the cognitive, affective and psychomotor needs of the learner. The cognitive needs of learners refer to the need for knowledge, which is the ability to recognize 
and recall specific facts, methods for organizing information and theories. The knowledge component in PE is imparted when teachers teach rules, tactics, strategies, terminology, history and current events, body systems and scientific concepts [13]. On the other hand, the psychomotor or techno motor needs of pupils which involves the learning of neuromuscular skill, is catered for when learners are involved in skill construction, skill stabilization and skill differentiation which are all components of skill learning [13]. The affective and social needs refer to the emotional and social aspects of learning. These are catered for when PE stimulates feelings about self and about others. It is important to note that PE is arguably the only subject which can educate students physically, mentally and socially. Physical Education (PE) is therefore no longer an appendage to the curriculum but a foundation subject for basic education [13].

Another misconception is the belief that PE is not an important academic subject. This arises from the fact that PE is not compulsory and there are no public examinations for the subject in most countries worldwide [12] including in Zimbabwe.

PE has also been confused with Sport, because the content of PE is from the generic sport forms and this has always been the traditional view [12]. This view has resulted in the belief that PE can be dispensed with since it is also done in the afternoon in most if not all Zimbabwean schools [12]. In this context PE is therefore seen as an unnecessary duplication of sport and hence a waste of valuable time.

Some people believe that taking part in PE leads to the development of unattractive bulging muscles [14]. Parents and teachers often believe that involvement in PE will make their students especially girls physically unattractive [14]. Many girls and women are sometimes said to express the same fears [14]. However this is a misconception because research has shown that bulging muscles depend on the presence of androgens in the body and women do not usually possess these hormones in amounts enough to cause muscular bulges [14]. Even boys would need to undergo heavy, structured training with weights to gain bulging muscles [14] and follow strict dieting regimes.

Other misconceptions which characterize the discipline of PE include the beliefs that, PE is a form of punishment (teachers who often ask student to do press ups or run laps as punishment seem to perpetuate this misconception); PE is a rest period between academic classes and that PE inculcates bad behavior due to the nature of dressing that characterize it.

\subsection{The PE syllabus and instructional materials}

Another important issue that has been reported to be a barrier in the delivery of PE in Zimbabwe is the PE syllabus. On the issue of the syllabus the lecturers and student teachers who were surveyed by the CDU [11] said that some schools did not even have a copy of the syllabus and the requisite teaching materials. Although the lecturers hailed the syllabus for being non prescriptive, they criticized it for being too open and not guiding enough in terms of what to teach to whom and when, which is a source of frustration and hence lack of confidence [11]. They said the syllabus does not define the basic common compulsory core curriculum components for all schools to ensure that uniformity prevails [11]. According to the CDU [11] the less prescriptive nature of the syllabus differentiates it from other curriculum subjects that are product oriented, prescriptive, communicative easy to understand and biased towards public examinations.

Musangeya et al [15] also observed that one of the major weaknesses of the schools PE syllabus is that it is a mixture of a teacher's guide and a teaching syllabus, making it difficult to interpret, administer and assess. The syllabus can only be understood and interpreted by competent, highly qualified and highly motivated PE teachers who have been exposed to curriculum development training [15]. Generally the Zimbabwean PE teacher is a generalist and in most cases is unable to interpret this syllabus [15]. The kind of specialist being described here is scarce in Zimbabwe [15]. The following example from the primary school 1997 PE syllabus derived from the grade one body management study area is case in point and illustrates how difficult it can be to interpret the syllabus, The example reads, "Plan and perform a range of simple actions in response to given tasks and stimuli" [16]. The syllabus does not clearly stipulate the "simple actions", "the tasks" and "the stimuli" the teachers' should use which can be very frustrating. These types of statements which characterize the whole syllabus are obviously very difficult to interpret and operationalize unless one is a highly trained and competent physical educator. The syllabus also has a very broad content base which makes it difficult to teach. It is not possible for a PE teacher to be an expert in every content area of the syllabus; this means that they have to rely on other teachers or outside personnel [6] unlike in other subjects.

The content of the syllabus has huge resource implications in terms of facilities, equipment and personnel to teach it [6]. As explained earlier this is a drawback in that the physical resources required by the physical education programme are very expensive and therefore beyond the reach of many Zimbabwean government schools [6]. Research in Zimbabwe indicates that instructional materials required for teaching PE are expensive and not readly available $[6,8]$. 


\section{IV.Conclusion}

It can be concluded from the review that the delivery of Physical Education (PE) in Zimbabwe primary and secondary schools is being impeded by a host of negative factors most of which are inextricably interlinked and bound together. The factors include the following inter alia: historical influences, lack of PE equipment and facilities, an unfavourable PE teachers training curriculum, negative attitudes towards PE by key stakeholders, lack of knowledge of what PE is, misconceptions about PE and lack of a user friendly PE syllabi that is also not supported by adequate teaching materials.

\section{Recommendations}

On the basis of the above findings the paper recommends the following strategies which if adopted by the concerned stakeholders will enhance the teaching of PE at primary and secondary school level in Zimbabwe:

Provincial Education Officers in charge of Sport as well as PE and Sports Coordinators at Cluster and District levels should conduct intensive advocacy training workshops and meetings at schools and/or during statutory district monthly School Heads' meetings and other fora in order to fully explain the meaning and importance of PE. This will help to alleviate the misconceptions, effects of historical influences such as scholasticism and the prevailing negative attitudes of teachers and heads of schools who end up acting as PE curriculum gate keepers.

The Ministry of Primary and Secondary Education should avoid lip service and make PE trully compulsory instead of writing policies and circulars which are disregarded willy nilly by both teachers and Heads of schools. The Ministry of Primary and Secondary Education should seriously consider incoporating elements of the subject in the national Zimbabwe School Examinations Council (ZIMSEC) grade seven general paper to begin with and also later making PE an examinable subject at secondary school level.This will ensure that teachers are compelled to teach the subject.

The government through the Ministry of Primary and Secondary Education in general and the School Development Associations (SDAs) in particular should prioritise investments in PE equipment and facilities. Special PE equipment and facilities levies can be introduced in the schools just like what the SDAs do with school bus levies and other special levies which they often ask parents to pay in addition to normal school fees and levies.

Donor agencies such as UNICEF should also consider providing PE textbooks, equipment and other teaching materials to all schools through the Education Transition Fund as they did with all the other curriculum subjects in Zimbabwe. UNICEF being a UN agency, should lead the way and be seen to be supporting the UN Charter by making PE a trully fundamental human right as well as supporting the spirit and essence of the $2004 \mathrm{UN}$ declaration which pronounced that 2005 be the international year for Physical Education. UNICEF can also consider using the Health Transition Fund to promote PE considering the widely reported health benefits of PE [17]. This can assist in reducing direct health costs since PE has the potential to reduce the risk of lifestyle or non-communicable diseases such as cardiovascular diseases, cancer, diabetes and conditions such as stress, anxiety and depression. PE is also believed to help prevent and reduce hypertension, control body weight, prevent and control osteoporosis and help manage chronic pain [17].

The Ministry of Higher Education and Technology should revise the PE teachers training curriculum so that it is standardised in all teachers' training colleges and also ensure that the teachers produced have enough competencies in the subject. The University of Zimbabwe to which currently all teachers colleges are associates, should develop policies and intensify its oversight role to ensure that the competencies of the teachers being produced in the subject are prioritised inorder to meet the required standards.

The CDU should revise the current PE syllabi in order to make them easier to interpret as well as making them prescriptive by defining the basic common compulsory core curriculum components for all schools in order to ensure that the syllabi are easily understood and that uniformity prevails as is the case in all other curriculum subjects that are product oriented, prescriptive, communicative, easy to understand and biased towards public examinations. In addition PE teachers should be provided with well organised and institutionalised in-service training courses that are both short term and long term and extensive. The CDU should provide detailed teachers' guides, manuals and rule books for various PE content areas and activities.

\section{References}

[1]. World Health Organization. Promoting active living in and through schools: A World Health Organization Statement. Denmark, Esbjerg; 1998

[2]. UNESCO. International Charter of Physical Education and Sport; 1978

[3]. SRC. Sport and Recreation Policy of Zimbabwe. 1996.

[4]. Ministry of Education, Sports, Arts and Culture. National Sports, Arts and Culture Secretary's Circular number 2 of 1994

[5]. Ministry of Education, Sports, Arts and Culture. National Sports, Arts and Culture Secretary's Circular number 5 of 2005 
[6]. Musangeya, E, Kupara, C.T, Tanyongana, C and Mumvuri, D. E. Historical perspectives in Physical Education and Sport. Harare, Zimbabwe Open University; 2000

[7]. Bucher C.A. Administration of Physical Education and Athletic program: 7th Edition. St Louis: The C. V Mosby Company; 1979.

[8]. Nziramasanga T.C. Report of the Presidential Commission of Inquiry into Education and Training. Government printers, Harare; 1999.

[9]. HIV \& AIDS in Zimbabwe. (cited 2013 October 2); Available from www.avert.org/hiv-aids-zimbabwe.htm

[10]. BBC news. Zimbabwe Inflation hits 100000 percent; 20th February; 2008

[11]. CDU. Curriculum Development Unit Survey Report. 1989.

[12]. Bucher CA. Foundations of Physical Education and Sport: 8th edition. St Louis: The C.V Mosby Company; 1983

[13]. Bucher and Thaxton. Physical education and Sport: Change and challenges, St Louis: The Mosby C.V Company; 1981

[14]. Coakley J.J. Sport in Society: Issues and controversies $4^{\text {th }}$ Edition. Toronto: Mosby College Publishing; 1990

[15]. Musangeya, E, Kupara, C.T, Tanyongana, C and Mumvuri, D. E. Critical issues in Programme Development for Physical Education and Sport, Harare, Zimbabwe Open University; 2000

[16]. Curriculum Development Unit. The primary Schools Physical Education Syllabus, Zimbabwe, CDU; 1997

[17]. Nhamo, E and Muswazi, T.M. The contribution of Sport and Physical activity towards the achievement of community health objectives. IOSR Journal of Sports and Physical Education (IOSR-JSPE) Volume 1, Issue 1 (Sep.- Oct. 2013) PP14-19 available from www.iosrjournals.org 